\title{
Science and technology policies: A tale of political use, misuse and abuse of traditional $R \& D$ indicators
}

\author{
ELENA CASTRO-MARTÍNEZ, FERNANDO JiMÉNEZ-SÁEZ, \\ FRANCISCO JAVIER ORTEGA-COLOMER
}

\author{
INGENIO (CSIC-UPV), Institute of Innovation and Knowledge Management, \\ Ciudad Politécnica de la Innovación, Camino de Vera s/n, 46022 Valencia, Spain
}

\begin{abstract}
Future political priorities for science and technology (S\&T) policy formulation usually rest on a rather simplistic interpretation of past events. This can lead to serious errors and distortions and can negatively affect the innovation system. In this article we try to highlight the riskiness involved in policy making based on traditional R\&D indicators and trends. We would emphasise that this approach does not take account of structural aspects crucial for the analysis of the innovation system. We examine the implications for science, technical and human resources policies of the political challenge of R\&D convergence in a peripheral EU region. Three scenarios are developed based on application of the same criteria to the trends observed in traditional $R \& D$ input indicators.
\end{abstract}

\section{Introduction}

Academics, politicians and consumers in the industrialised countries are paying greater attention to science and technology (S\&T) policies, which is resulting in a widespread tendency to devise and use indicators to improve and consolidate policy design and evaluation. Looked at in isolation, this could be seen as positive, since the existence of more indicators can result in better designed more tailored policy. It also helps in evaluating outcomes more reliably, on the basis of specific measurements that demonstrate achievement. However, some caution is called for in applying these indicators [FELLER \& GAMOTA, 2007], because a reliance on past events to set future priorities can lead to serious errors that could distort the formulation of policies.

One cause of such distortion is the application of neoclassical-type measures, such as the decision to subsidise R\&D activities within a short-term horizon on the basis of a structuralist-evolutionary inspired policy design [LIPSEY \& CARLAW, 1998], which can have consequences that extend beyond a government's term of office (commonly four years in Spain).

A second cause of distortion, which is clearly related to the first, but is far more compromising for those in the government, arises when innovation system indicators

Received June 17, 2008; Published online April 16, 2009

Address for correspondence:

ELENA CASTRO-MARTÍNEZ

E-mail: ecastrom@ingenio.upv.es 
are used for political ends; that is to say, with a time horizon corresponding to the life of the government in power. The measures derived from these indicators may have very different medium and long-term repercussions than those foreseen for the immediate four-year period. The common denominator in many of these cases is how the ratio between gross expenditure on R\&D/gross domestic product (GERD/GDP) is used as the basis for political agendas. There are examples in the political messages embodied in proposals such as the Lisbon Strategy, which fixes the GERD/GDP target for the European Union at $3 \%$ by 2010 [COMMISSION OF THE EUROPEAN COMMUNITIES, 2003], and in the Compromiso Ingenio 2010 report, which sets the target at 2\% for Spain [Ministerio DE LA PRESIDENCIA, 2005]. Following this fashionable trend several Spanish regions ${ }^{1}$ have used these indicators to establish their goals for science and technology policies. For instance, the Valencian Government planned in its 2001-2006 $R \& D$ Plan to reach the target of $2 \%$ in 2006 [GENERALITAT VALENCIANA, 2000] and recent statistics show that the actual value for this year was just $0.8 \%$ [INE, 2008a].

Within this context, we attempt to show the consequences of simplistic political forecasts based on R\&D indicators, by analysing the future evolution of the Valencian Innovation System (VIS), ${ }^{2}$ starting from a baseline determined by current R\&D indicators. We intend to demonstrate the structural consequences, which are not considered in such a political exercise, and discuss how they translate into unrealistic goals.

The article is organised in five sections. First, we describe the theoretical framework for the development, interpretation and application of R\&D indicators. In order to put the analysis into context, we provide a brief description of the current characteristics of the VIS and then propose some hypotheses about the likely evolution of key indicators. These hypotheses are the basis for three scenarios, which will lead to and support certain conclusions and consequences.

\section{Theoretical framework}

The need to develop methodologies to improve the design and implementation of S\&T policies has been felt at all levels in Europe - regional, national and supranational - and the fashioning of new instruments to achieve policy objectives has become imperative. At the same time, we are witnessing a change of paradigm in the political context. Whereas, in the past, certainty and long-term considerations dominated the way that political actions were conceived, today the design of actions to promote $R \& D$ activities is being determined more and more by uncertainty and medium-term considerations.

\footnotetext{
${ }^{1}$ More than $50 \%$ of Spanish regional R\&D plans have used this sort of approach to set R\&D goals. Source: http:/www.micinn.es/ciencia/jsp/plantilla.jsp?area=ccaa\&id=5.

2 The political unit within Spain known as the Valencian Autonomous Region (or Comunidad Valenciana in Spanish) will be referred to simply as 'Valencia', which coincides with one of the NUTS-2 EU regions.
} 
Neoclassical-type measures, designed to encourage R\&D activities through subsidies or other types of incentive for countering shortcomings in the market system (market failures), are giving way to other kinds of actions that are intended to have a structural impact and to affect the behaviour of responsible economic operators. Thus, politicians are trying to change both the ideological framework and the design of their actions [LIPSEY \& AL., 2005]. However, often these changes are introduced too suddenly, and in the absence of adequate experience in the design and implementation of R\&D incentives, can have unfortunate consequences. There is a lack of consistency between policy design, which may be in harmony with structuralist-based ideas, and the actions proposed to achieve the objectives of the policy, which tend to hark back to neoclassical-based mechanisms [MOREAU, 2004]. This lack of synchrony between policy design and policy instruments has prompted numerous studies in the literature on technological change [TASSEY, 2001; MOLAS-GALLART \& DAVIES, 2006] and has led some observers to advise caution to some of the politicians and managers involved. This lack of consistency also reflects the neoclassical interpretation of R\&D activities. Structuralist-based policy implementation requires cultural change at both policymaking level and among the rest of the economic agents involved in the innovation system [ALBERTOS, 2002] if it is to succeed in the long term. Furthermore, the use of narrow input indicators as a basis for a 'policy message' regarding the system's performance, has long been criticised. According to LUNDVALL (1992:6): "There are two obvious problems with this indicator [GERD/GDP]. First it reflects only an input effort and does not say anything about what comes out of the effort. Second, R\&D expenditure is only one kind of relevant input to the process of innovation-learning in connection with routines activities may be more important than $R \& D$ ".

The influence of neoclassical theory on politicians remains strong and they generally assume a direct and positive relationship between GERD/GDP effort and innovation system performance, ignoring other (even more) important factors such as the relationships among the system's agents [MEYER, 2006; LEYDESDORFF \& MEYER, 2007; WONG \& HO, 2007] among others, whose influence on performance of the innovation system is widely acknowledged. In addition, application of this indicator is easy and to a great extent simplifies the elaboration of policy messages. However, the innovation system is complex, with connections among many variables and in many different ways, which are not adequately reflected in these policies [GODIN, 2007; MARTIN, 2008].

The need to refashion S\&T policy has been accompanied by a growth in the design and accumulation of indicators to assign values to diffuse activities such as R\&D and its medium and long-term implications [KATZ, 2006]. The standard manuals for the measurement of R\&D and innovation activities fail to provide sufficient guidance. ${ }^{3}$

\footnotetext{
${ }^{3}$ We refer here to the Frascati Manual [OECD, 2003] for defining and characterising R\&D activities, and the Oslo Manual [OECD, 2005], which focuses on innovation.
} 
Indeed, a large part of the literature on the study and application of indicators is devoted to the use of functional, behavioural and performance indicators in political programmes and activities [SHAPIRA, 2003; RUEGG \& FELLER, 2003] among others. There is also a healthy literature that explores and analyses the political uses (good and bad) to which indicators have been put [Godin, 2002; CHOBAnOva, 2006]. What all these studies have in common is that they find there is a discrepancy between the political messages, which have a time horizon limited to one term of legislative office, and the way that certain indicators of the current state of an innovation system are used to provide 'objective' support for these messages. The greatest risk lies in the inability to foresee the medium and long-term effects of these measures on others that are related but are not taken into account by policy makers.

The latter literature aims at cautioning politicians and policy-makers against shortsighted, misapplication of these indicators while at the same time seeking to provide a more solid foundation on which to formulate S\&T policy in such a way that the messages it carries will be consistent with the evolution and significance of multiple interrelated indicators.

Managers and politicians have a responsibility to pursue policies through their entire life cycle, from initial orientation, through design and management planning, until the end, which only comes when the results are analysed [DíEZ, 2002]. This final outcome of the policy cycle can then serve as input for a new policy cycle. Throughout the iterative process, it is essential that actions are fed and supported by accurate, adequate and timely information.

The literature on the economics of technological change has established the defining characteristics of R\&D activities and had proposed new schools of thought that have influenced and will continue to influence the design of policies for stimulating R\&D. Finally, it has shown that policies with a medium or long-term horizon (depending on the activity in question), are more likely to succeed and be consistent with the assumptions on which they are based.

\section{Summary of the Valencian Innovation System (VIS)}

To put the analysis in this paper into context we describe some features of the VIS. Valencia is a peripheral region of the $\mathrm{EU}^{4}$ and has been examined in depth [FERNÁNDEZ-DE-LUCIO \& AL., 2001; GARCÍA-ARACIL \& AL., 2002]. In demographic terms, Valencia is home to $10.6 \%$ of the population of Spain; ${ }^{5}$ the percentage of the employed population is $10.8 \%$ and it accounts for $9.7 \%$ of the total Spanish GDP. The seeming inconsistencies in these percentages are because Valencian per capita income

\footnotetext{
${ }^{4}$ Defined as the type of EU region not included in the "Blue Banana Belt" [BRUNET, 2002].

${ }^{5}$ All figures are for 2005 .
} 
is about $90 \%$ of the national average. The unemployment rate, which is a significant social indicator, is $9 \%$, slightly lower than the national average of $9.2 \%$.

In terms of the production structure, the agriculture and energy sectors in Valencia are of minor importance: they represent less than 5\% of GDP and a little more than $4 \%$ of employment, hence less than in Spain nationally. On the other hand, the weight of industry is higher than the national average (18\% compared to $16.7 \%)$. The breakdown of the figure for industry shows that there is a large set of medium and low-tech technologies $^{6}$ (non-metallic mineral products, particularly ceramics; textiles, leather, shoes and foodstuffs) that account for $50 \%$ of the total; knowledge-intensive sectors (chemicals; mechanical, electrical and electronic machinery and equipment; manufacture of transport equipment) comprise only $4 \%$ of GDP and $3.5 \%$ of employment. The construction sector and non-knowledge-intensive services (commerce, hotel and catering trades, estate agencies, etc.) account for almost $50 \%$ of GDP. We discuss the implications of this structure for R\&D activity in a later section of this paper.

Another factor important to the production sector is education and training of human resources. In 1994, the proportion of university graduates in the Valencian workforce was lower overall than the Spanish average (5.5\% vs 7.7\%) [MAS \& AL., 2007], though with large variations in some sectors such as industry and services. The figures had improved in 2004, by which time the differences between Valencia and Spain as a whole had been reduced to the point where graduates represented $10.1 \%$ of the Valencian workforce. In some sectors the proportion even surpassed the national average, for example agriculture (5\% vs $1.9 \%)$, construction $(4.5 \%$ vs $3.2 \%)$ and nonsales services (33\% vs 29\%). The non-sales services sector (health, education, government, etc.) has the highest percentage of workers with higher education, both in Valencia and in Spain.

Against this background, we examine the main Valencian R\&D activity indicators for 2005 (see Table 1). The level of the resources allocated to R\&D, both financial and human, is somewhat lower than nationally -1.5 points according to the social and economic indicators referred to above, which explains why the indicators for GDP and the number of employed are below the national average. The lowest Valencian indicator is for innovation; this is largely due to the production structure [CASTRO-MARTínEZ \& FERNÁNDEZ-DE-LUCIO, 2006], and especially the weakness in the medium and hightech manufacturing sectors and the scarcity of medium-large firms.

\footnotetext{
${ }^{6}$ We adopt the EUROSTAT classification (http://europa.eu.int/estatref/info/sdds/en/htec/htec_agg_nace.pdf) of high-tech (HT) manufacturing sectors: pharmaceuticals; office machinery and computers; radio, TV and communication equipment; apparatus, medical, precision and optical instruments, watches and clocks; aircraft and spacecraft, and of medium-high-tech (MHT): chemicals other than pharmaceuticals, machinery and equipment, electrical machinery and apparatus; motor vehicles; other transport equipment. The following are classed as HT knowledge intensive services: post and telecommunications; computer and related activities; R\&D.
} 
Table 1. Main indicators of R\&D and innovation activities in 2005

\begin{tabular}{lccc}
\hline Indicator & Valencia & Spain & $\begin{array}{c}\text { Valencia/Spain } \\
(\%)\end{array}$ \\
\hline Total GERD (millions of euros) & & $10,196.90$ & 8.5 \\
Business Enterprise Sector* & 867.67 & $53.8 \%$ & 5.9 \\
Government Sector & $37.6 \%$ & $17.0 \%$ & 6.6 \\
Higher Education Sector & $13.2 \%$ & $29.0 \%$ & 14.4 \\
GERD/GDP (\%) & $49.2 \%$ & 1.13 & 8.5 \\
R\&D personnel (FTE**) & 1.0 & 174,773 & 8.7 \\
Business Sector & 15,256 & $43.3 \%$ & 7.2 \\
Government Sector & $35.7 \%$ & $16.8 \%$ & 6.2 \\
Higher Education Sector & $13.0 \%$ & $39.1 \%$ & 11.7 \\
R\&D personnel per 1,000 working population & $51.3 \%$ & 8.4 & 8.4 \\
Researchers (FTE) & 5.5 & 109,72 & 6.3 \\
Business Sector & 9,194 & $32.1 \%$ & 6.8 \\
Government Sector & $24.1 \%$ & $18.6 \%$ & 10.4 \\
Higher Education Sector & $15.0 \%$ & $49.2 \%$ & 6.3 \\
Researchers per 1,000 working population & $60.9 \%$ & 5.3 & \\
R\&D expenditure per researcher (euros/FTE) & 4.1 & 92,936 & \\
Total expenditure on innovation (millions of euros) & 94,375 & 13,636 & \\
Total expenditure on innovation (\% of GDP mp $\left.^{* * *}\right)$ & 856 & 1.5 & \\
\hline
\end{tabular}

* The business sector includes non-profit private organisations; however, they account for less than $1 \%$ of the Spanish R\&D effort.

**FTE: Full-Time Equivalent

***GDP $\mathrm{Gp}_{\mathrm{mp}}$ : Gross Domestic Product at market prices

Sources: Spanish National Statistic Institute (INE, 2007a; 2007b) and authors' calculations.

Although the figures for Valencia are below Spanish average, all indicators have improved substantially since the mid 1990s, and especially from 2002. The average compound rate of increase in R\&D expenditure for the period 1995-2005 was 15\%, although personnel did not kept pace: average compound growth rate of R\&D personnel was only $11 \%$, and that of researchers $10 \%$. The VIS is also characterised by a high percentage of SMEs (like Spain and other EU countries, with more than $89 \%$ of the total number of firms) but, contrary to Spain and EU countries, R\&D effort is concentrated in these types of firms. EU firms with at least 200 employees perform $84 \%$ of Business Enterprise R\&D (BERD), and the figure for Spain is 55\% accounting for $43 \%$ of researchers. Valencian large firms are responsible for only $16 \%$ of BERD and they employee $9 \%$ of researchers.

Table 1 also gives the distribution of R\&D expenditure, personnel and researchers by sectors. The organisation of the R\&D effort in Valencia has advanced considerably since the 1990s, when industry and business were responsible for barely $30 \%$ of expenditures and employed only $13 \%$ of researchers. Nevertheless, and despite considerably increased effort in the last decade, Valencia has not managed to catch up to the Spanish national averages. The gap is most marked in number of researchers, a key factor in this type of activity. In terms of production structure, Industry in Valencia is mainly medium and low-tech, and this has a significant impact on the level of expenditure that the business sector devotes to R\&D. 
If we look at the number of researchers with a $\mathrm{PhD}$, we can see that the Valencian higher education system produces on average 700 doctor graduates [INE, 2008b] per year which is around $10 \%$ of the total for Spain.

Within Europe, EU indicators for comparing regional innovation systems assign Valencia a relatively low ranking. Table 2 presents the values for this indicator and the factors that contribute to it. Its overall value of 0.36 places Valencia in 130th position among the 208 regions in the EU-25; the lowest relative contributors to the overall index are percentage of employment in medium and high-tech service industries and percentage of R\&D expenditure by the business sector as a proportion of GDP.

Table 2. Valencian innovation system performance as ranked on the European Regional Innovation Scoreboard (RIS), 2006

\begin{tabular}{ll}
\hline & Value \\
\hline Revealed Regional Summary Innovation Index (RRSII) & 0.36 \\
$\%$ of science graduates in population aged 20 to 29 & 0.06 \\
$\%$ of population aged 25 to 64 taking continuing education & 0.07 \\
$\%$ of employment in medium and high-tech manufacturing industries & 0.05 \\
$\%$ of employment in medium and high-tech service industries & 0.03 \\
$\%$ of R\&D expenditure by the public sector as a proportion of GDP & 0.07 \\
Num of R\&D expenditure by the business sector as a proportion of GDP & 0.03 \\
\hline
\end{tabular}

Source: Commission of the European Communities, 2007

Another revealing indicator is the percentage of Valencian BERD financed by government (4\% in 2005) compared to Spain (13.5\%) and the EU-25 (8.4\% in 2004). The number of Valencian innovating firms ${ }^{8}$ which received public funding for innovation activities in 2003-2006 increased to 1,316 (22\% of the total) [ALTO Consejo Consultivo De LA CV, 20089 ${ }^{3}$ out of a total of 5,993 innovating firms, while the EU-25 and Spain registered 9\% respectively. This shows that Valencian BERD is much more fragmented than Spanish or EU BERD and the insignificant proportion in terms of individual firms, is irrelevant.

Again, we should emphasise the relatively small role of the most R\&D intensive sectors, namely the high-tech (HT) and medium-high-tech (MHT) sectors. The number of HT and MHT enterprises in Valencia $(2,800$, or $12.3 \%$ of the Spanish total) is similar

\footnotetext{
${ }^{7}$ Based on number of doctoral graduates from the Valencian Higher Education system 2002-2006.

${ }^{8}$ According to [INE, 2007c], innovating firms are those that carried out innovation activities during the three years prior to the survey. The firm sample is drawn up from a set of all firms potentially capable of carrying out R\&D activities plus firms with more than 200 employees and a random sample extracted form DIRCE (INE publication that gathers information on the total number of business firms in Spain - in this case the Valencian Region). This produced a sample of around 43,000 firms.

${ }^{9}$ INE conducts the Innovation Survey and the Valencian Regional Government requests the data on its region, which is used to produce an annual report on R\&D and innovation activities in the Valencian Region.
} 
to other Spanish regions, but only 483 of them are truly HT and their turnover and economic importance are limited. In terms of workers, the numbers employed in HT and MHT represent only $7.3 \%$ of total Spanish employment and $5.6 \%$ of Valencian employment; almost all of this is in the MHT and service sectors. The number employed in the true HT sectors is 6,800 out of a working population of 2 million [INE, 2007b]. In Spain overall, $67 \%$ of business and industry R\&D expenditure is concentrated in the HT and MHT sectors, as well as $64 \%$ of personnel and $70 \%$ of researchers ${ }^{10}$ (the EU-25 is in the middle range of this indicator; and in Valencia, these sectors account for $51 \%$ of R\&D expenditure and employ $54 \%$ of the personnel - FTE). Valencian industry is dominated by the traditional sectors and by policies that were framed many years ago, which channelled R\&D into the setting up of a network of technology centres to provide $R \& D$ services for the firms in those sectors.

\section{Data and methodology: potential future scenarios for the Valencian R\&D effort}

In what follows, we propose a forward-looking analysis of how gross expenditure on R\&D activities (GERD) and number of researchers, which are the subject of policy discourse, may change. These are the benchmarks that are usually used when establishing the main objectives of S\&T policies. In this way we try to show the challenges posed by seeking to achieve specific values for GERD as a percentage of GDP, and the effect on other directly related R\&D activity indicators. Three possible scenarios can be envisaged for these two key variables: (a) conservative change, based on developmental hypotheses that fit the trends established in the region in recent years; (b) moderate change, which supposes a faster rate of development that is more in line with Spanish S\&T policy challenges; and (c) optimistic change, which would bring Valencia up to the present average for the EU-25 and is based on meeting the EU targets foreseen in the Lisbon Strategy. This last is also the target for Spain proposed in the Ingenio 2010 programme [MinisTERIO DE LA PRESIDENCIA, 2005]. In all three cases the time horizon for our analysis is 2010 .

In all these hypotheses we apply linear regressions. We are not trying to do an econometric modelling, but rather we want to simplify the number of initial variables and propose growth criteria that are easily adjustable, but retain the same sorts of simplifications and assumptions made in policy discourse. The aim is to try to demonstrate the consequences of these messages. The hypotheses can be summarised as follows.

1. Forecast evolution of regional GDP. The data for the 2005 baseline are taken from Contabilidad Regional de España, Base 2000 [INE, 2007d]. The forecasts for growth in 2006-2008 are based on a report by HISPALINK [2007]; those for 2009 and

${ }^{10}$ Source: [INE, 2007b]. www.ine.es. 
2010 are based on the OECD forecasts for Spain (Hispalink does not have projections for these years). Table 3 shows the changes in GDP growth rates in Valencia starting from the base year 2005 .

Table 3. Forecast changes in rate of Valencian economic growth, 2006-2010

\begin{tabular}{lc}
\hline Year & Annual rate of increase in the volume of $\mathrm{GDP}_{\mathrm{mp}}(\%)$ \\
\hline 2006 & 3.6 \\
2007 & 3.3 \\
2008 & 3.1 \\
2009 & 2.9 \\
2010 & 2.9 \\
\hline
\end{tabular}

Sources: Hispalink (for 2006-2008) and OECD (for 2009-2010)

2. Forecast evolution of Gross Domestic Expenditure on $R \& D$ (GERD) in relation to the GDP (GERD/GDP ratio). Based on the above forecast, we develop three alternative vectors of change, shown in Table 4. They start from a base GERD/GDP of $0.99 \%$ in 2005 . The conservative forecast would suppose a GERD/GDP of $1.2 \%$ in 2010, which corresponds to an increase in GERD that is in line with the trend in Valencia over the last 10 years. The intermediate (moderate) prediction would be $1.32 \%$, which is the figure that Spain is expected to reach if the trend over the last 10 years continues. The optimistic forecast would expect a ratio of $2 \%$ by 2010 , which corresponds to present EU levels, and is also as forecast in Ingenio 2010.

Table 4. Forecast growth in Valencian GERD/GDP ratio, 2005-2010 (\%)

\begin{tabular}{lllllll}
\hline Scenario & 2005 & 2006 & 2007 & 2008 & 2009 & 2010 \\
\hline Conservative & 0.99 & 1.03 & 1.07 & 1.12 & 1.16 & 1.20 \\
Moderate & 0.99 & 1.06 & 1.12 & 1.19 & 1.25 & 1.32 \\
Optimistic & 0.99 & 1.19 & 1.39 & 1.60 & 1.80 & 2.00 \\
\hline
\end{tabular}

Source: Authors' calculations

3. Hypothetical structural evolution of GERD. In this hypothesis, a second variable factor is introduced into the three scenarios, namely the structural evolution of GERD implementation, divided between the business sector (mainly business firms) and the public sector (including higher education and government). A comparative examination of R\&D indicators in different countries shows that a higher percentage of GERD is performed by enterprises in the more advanced countries than in the less developed ones [LEGLER \& AL., 2006]. An examination of the present situation in Valencia reveals that - as in other regions with relatively low levels of R\&D effort - most of the effort, in terms of both R\&D expenditure and number of researchers, comes from the public sector. Therefore any growth scenario must take account of which sectors are presumed 
to undergo the greatest increases. In line with this, three possible sectoral distributions for future GERD can be projected (Table 5). The first assumes that the region maintains the structural change trend established over the last 10 years, which shows a distinct bias towards the scientific sector, which accounts for $62 \%$ of GERD. The second represents progress from the current situation to a level matching the present national average ( $45 \%$ scientific and $55 \%$ production). The third envisages a progression in which the Valencian structure would match the present EU average, and the business sector would account for $64 \%$ of GERD. In all cases, R\&D carried out by non-profit private institutions is not included.

Table 5. Forecast changes in GERD structural distribution, 2005-2010

\begin{tabular}{lllll}
\hline & \multicolumn{2}{c}{2005} & \multicolumn{2}{c}{2010} \\
\hline Structural division and \% & PS & BS & PS & BS \\
Conservative scenario & 62 & 38 & 59 & 41 \\
Moderate scenario & 62 & 38 & 45 & 55 \\
Optimistic scenario & 62 & 38 & 36 & 64 \\
\hline
\end{tabular}

PS: Public sector; BS: Business sector

Source: Authors' calculations

4. Hypothetical development of researchers' working resources (annual $R \& D$ expenditures per researcher in each sector). To quantify the number of VIS researchers available for developing R\&D activities under each of our scenarios, we use the ratio of working resources per researcher in each sector, i.e. annual R\&D expenditure divided by number of researchers. The ratio differs greatly among sectors. We extrapolated the results for each sector, for each of the three scenarios, based on trends in the 10 years from 1995-2005. We should point out that we base our forecast of the trends in these ratios on linear regressions, to try to capture the sorts of political assumptions made in the setting of political priorities. The conservative scenario applies the Valencian trend, the moderate scenario the Spanish trend, and the optimistic scenario the trend in the EU. Table 6a summarises the start and end points for each scenario and each sector; Table $6 \mathrm{~b}$ presents the respective linear regression equations. Although our linear regression estimates are based on a fairly long time span (10 years previous to 2005) due to the somewhat erratic behaviour of the ratio for the business sector, the results are not robust (see the $\mathrm{R}^{2}$ indicator values for the business sector scenarios in Table $6 \mathrm{~b}$ ). 
Table 6a. Forecast development of working resources per researcher in Valencia (thousands of Euros per researcher and year)

\begin{tabular}{lcccc}
\hline Year & \multicolumn{2}{c}{2005} & \multicolumn{2}{c}{2010} \\
\hline Sectors & PS & BS & PS & BS \\
Conservative scenario & 77.6 & 147.4 & 88.6 & 132.8 \\
Moderate scenario & 77.6 & 147.4 & 84.6 & 140.8 \\
Optimistic scenario & 77.6 & 147.4 & 90.0 & 159.0 \\
\hline
\end{tabular}

PS: Public sector; BS: Business sector

Source: Authors' calculations

Table 6.b. Linear regression equations representing the evolution of Public and Business sectors

\begin{tabular}{lll}
\hline Public sector & Equation & $\mathrm{R}^{2}$ \\
Conservative scenario & $\mathrm{y}=2.20 \mathrm{x}+48.8$ & 0.73 \\
Moderate scenario & $\mathrm{y}=1.41 \mathrm{x}+43.9$ & 0.69 \\
Optimistic scenario & $\mathrm{y}=2.48 \mathrm{x}+106.3$ & 0.95 \\
Business sector & Equation & $\mathrm{R}^{2}$ \\
Conservative scenario & $\mathrm{y}=-2.91 \mathrm{x}+149.2$ & 0.19 \\
Moderate scenario & $\mathrm{y}=-1.32 \mathrm{x}+169.7$ & 0.23 \\
Optimistic scenario & $\mathrm{y}=2.32 \mathrm{x}+200$ & 0.57 \\
\hline
\end{tabular}

Source: Authors' calculations

On the basis of the above forecasts, and assuming that the first (GDP development) is a constant, we can generate 27 scenarios based on combinations of the three proposed alternatives for each of the three hypotheses. Below we present the results for three of the 27 possible scenarios; these are based on application of the same criteria (conservative, moderate or optimistic) to all the variables considered: (1) changes in the GERD/GDP ratio; (2) distribution of R\&D expenditure between the public and business sectors; and (3) annual R\&D expenditure per researcher in each sector. We believe that this approach illustrates the potential consequences of each of the scenarios for the VIS, as well as the interrelationships among the variables.

\section{Results}

Figure 1 depicts the growth that would occur in the public sector if the present trend were to continue (i.e., the conservative scenario). Ultimately, there would be a convergence with the optimistic scenario in absolute, but not relative terms. Were this to happen, the levels of public sector expenditure and the drain on the public coffers would become unsustainable. The curve representing the optimistic scenario shows that 
in this scenario there is a simultaneous reduction in the sectoral distribution of expenditure and increase in researchers' working resources to the point where they coincide with European levels.

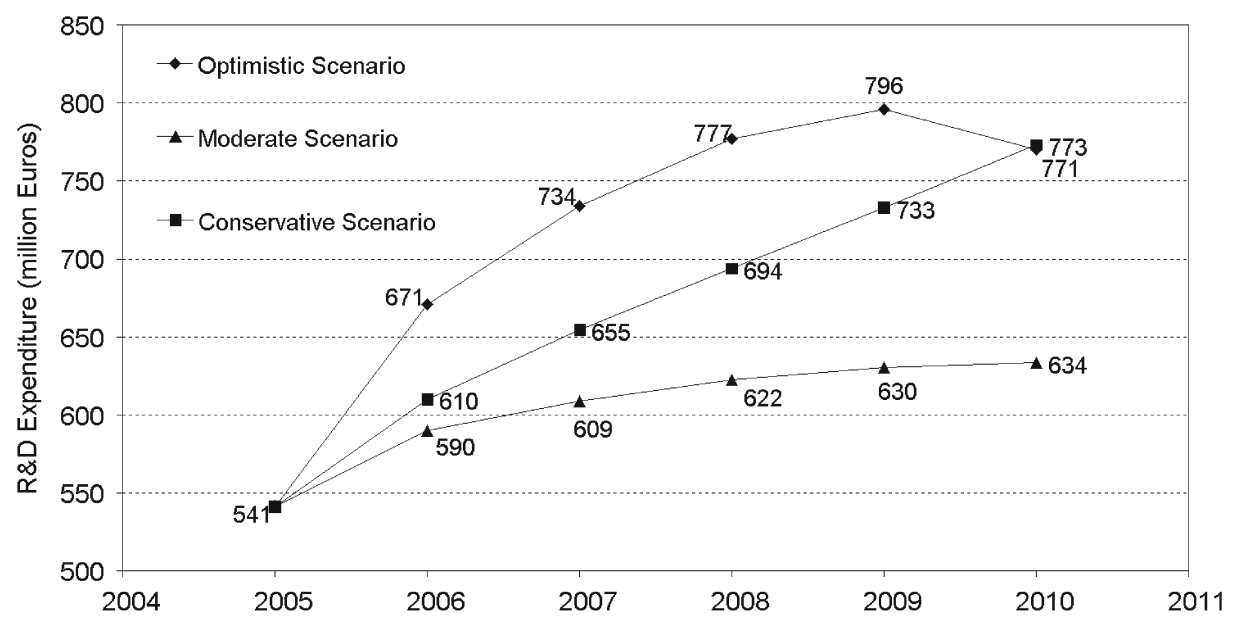

Figure 1. Projection of Valencian Public Sector R\&D Expenditure

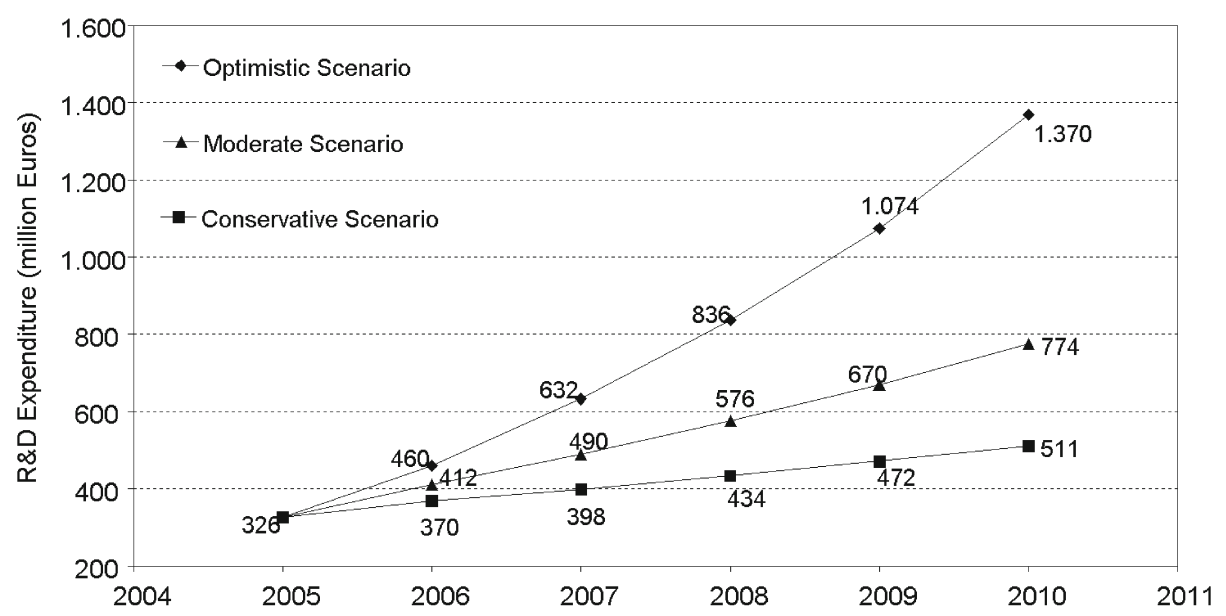

Figure 2. Projection of Valencian BERD 


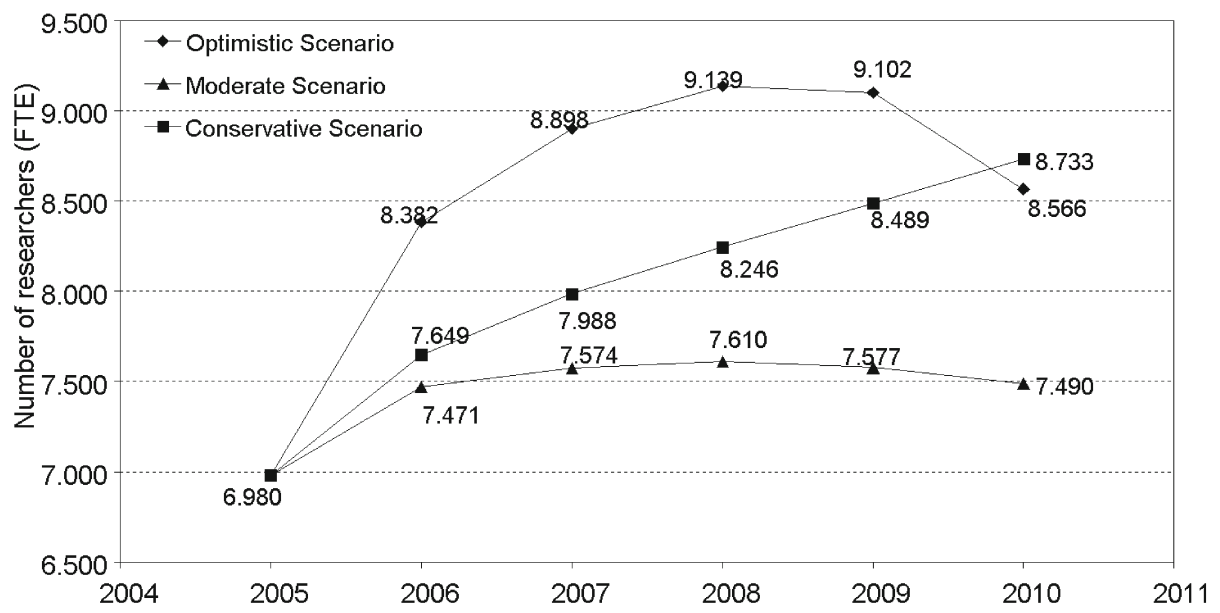

Figure 3. Projection of the number of researchers in the Valencian Public Sector

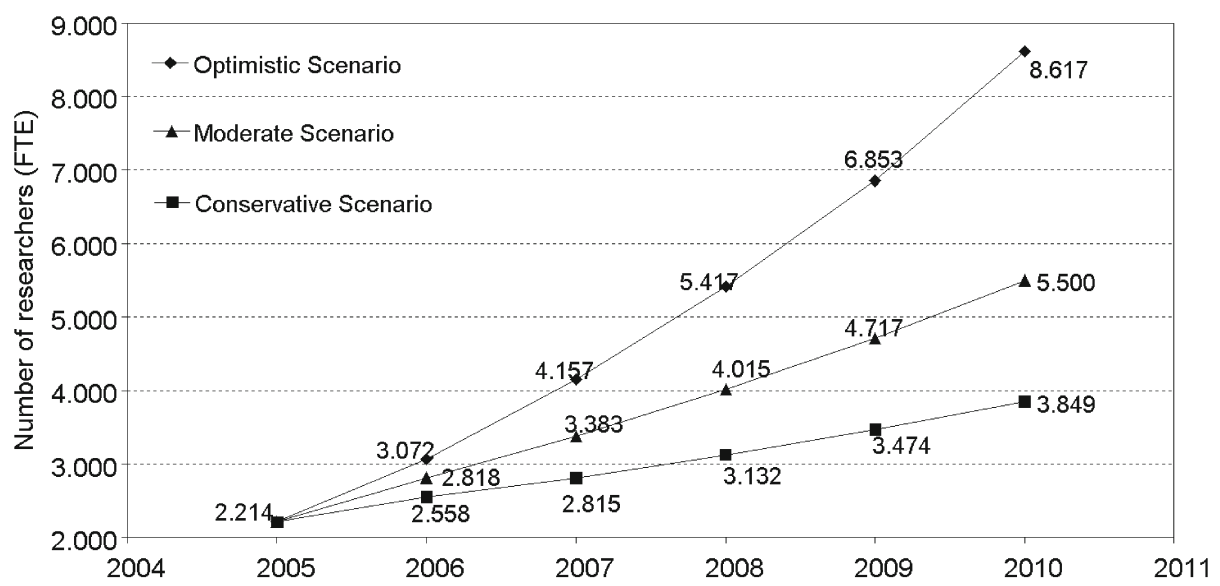

Figure 4. Projection of the number of researchers in the Valencian Business Sector

Figure 2 depicts the evolution of Valencian BERD. The optimistic scenario (i.e. achieving EU levels) would require a tripling of BERD in five years. Based on the current Valencian production structure, which is mainly mid and low-tech sectors, this is hardly realistic. The firms in these sectors have experienced annual growth of $12 \%$ during the past decade; thus annual growth rates of $20 \%$ and $30 \%$ (respectively for the moderate and optimistic scenaries, Figure 2) for BERD would be unviable. 
Figure 3 depicts the changes in the number of researchers (FTE) in the public sector under the three scenarios. It shows that the conservative scenario assumes a continuation of the present trend and hence a progressive increase. This would result in an unsustainable level as it would involve and increase of around 50\%, more than $90 \%$ of which would have to be financed from public funds. The moderate scenario envisages a level of growth that would be more acceptable to government, while the optimistic scenario would also be very difficult to achieve in the public sector.

In terms of business sector researchers (Figure 4), even the conservative scenario foresees a net increase of more than 1,600; while the moderate and optimistic scenarios - and especially the latter - call for substantially bigger increases. The graph in this figure shows that effort that would be required to catch up with the EU-25 researcher numbers (and with the corresponding GERD) would be truly enormous. Therefore, no matter how desirable the target might be, it would in practical terms be out of the question in such a short time span. If we correlate this information with the number of $\mathrm{PhD}$ students graduating per year in the Valencian region (around 700), and make the rather simplistic assumption that all researchers have a $\mathrm{PhD}$ degree, we can see that the Valencian higher education system would not have the capacity even to cover the conservative scenario (a net increase of 3,388 researchers for the period analysed: 1,753 for the public sector and 1,635 for the business sector) and certainly would not be able to satisfy the moderate and optimistic scenarios (near to 3,800 and 8,000 respectively from Figures 3 and 4).

In terms of policy, the optimistic scenario is completely unattainable since it would entail very profound changes, both structural and cultural, in the region. This would be completely impossible within a four year legislative term. Furthermore, such deep changes could only be envisaged if the policy were targeted not at any one particular sector, but were to be the result of unanimous agreement among all the stakeholders: political groupings, business people, trade unions, etc. Unfortunately, such agreement would be beyond the control of any party; even if it were achievable, results could not be expected to come to fruition in such a short period of time.

The moderate scenario falls within the scope of political planning. However, it fails in terms of industrial structure: the region's productive economy seems not to be capable of attracting or creating HT and MHT enterprises, which are those firms whose innovations are mainly based on the promotion of R\&D activities. In addition, the structure of firms would need to change, since we have observed that mid-size firms execute the larger proportion of BERD and employ a higher number of researchers. We have also observed that researchers in the public sector are not trained in the specialities that are most in demand. In other words, regional S\&T policies are not providing incentives for researcher training tailored to demand (either present or likely future demand) from the new technology-based enterprises. It is true that the moderate scenario would require a great effort from both the production sector and the public 
sector authorities; however, firm commitment to it would bring very important changes that in the long term could become a sound basis for the much deeper and more lasting change envisaged in the optimistic scenario.

\section{Conclusions}

We have tried to demonstrate that the political use of basic R\&D indicators to support a short-term political agenda is meaningless. The analysis in this paper should be of interest to politicians in highlighting that some R\&D indicators are no more than input measures and do not necessarily (directly and positively) correlate with the performance of the innovation system. Furthermore, the use and interpretation of these indicators ignores the connections with other important aspects of the innovation system, which, if not considered, will lead to misleading and inaccurate policy messages, which could have dramatic consequences in the medium-long run. This simplistic analysis makes it clear that the consequences of certain political engagements looking only at the two sides of S\&T policies, financial and human resources and how they influence each other, can be negative.

The specific case we analysed was the hypothetical evolution, in a five year period, of the VIS in terms of three possible outcomes. Our baseline was constructed by information from the previous 10 years. Each scenario shows the effort required to reach the goals proposed, and makes it clear that in some cases this is both unfeasible and even could be harmful to the system. It is clear that S\&T policies should be formulated on structural-based measures which must be consistent with the nature of R\&D activities, and able to influence the behaviour of the economic actors in the public and business sectors and in the medium and long term. Descriptive indicators are not enough. Effective policies should be seen within a longer time frame than a government's term of office. In our scenarios, we showed that the long-term consequences of some policy goals can be unrealistic if not harmful. Short-sighted use of analytical indicators may produce inaccurate, damaging and misleading policy advice.

We would highlight two preliminary conclusions regarding our methodology, which relate primarily to the quality of the data. Our baseline information is fairly reliable; it is data that have been audited for budgetary purposes, which is normal for public sector activities. However, the quality of the business sector information varies greatly and therefore makes attempts to forecast trends and demonstrate fits unreliable. Also, applying statistical techniques, no matter how sophisticated, to such erratic and unreliable initial data leads to results that are not robust. This in turn leads to conclusions that do not make economic sense, and means that as a basis for policy formulation they are ill-advised. 
In this context, it should be assumed that politicians' forecasts tend to be rather general and do not distinguish between the public and business sectors. In the former sector, the data on R\&D activities are fairly carefully monitored and their evolution is more predictable. In the business sector, it is difficult to check the behaviour of the variables, because they depend for the most part on the efforts of the enterprises themselves (even when government policies in the form of R\&D subsidies and incentives are present). The result is likely to be a political message that lacks robustness because it is based on unreliable data, but which nevertheless sets some overall objectives. In the short term these objectives may seem highly desirable, but they could have some hidden harmful long term effects on the innovation system in the form of increasing imbalances. We also showed that there is a low proportion of publicly funded Valencian BERD, which reflects the low level of influence of S\&T policy. A change in the cultural behaviour of firms regarding innovation activities is required. Such change might be driven by policy incentives to promote a different consideration of business innovation activities.

We must emphasise that it is difficult for policy to have an effect on the business sector participants in an innovation system when the initial forecasts that determine the key variables in a developmental scenario are unreliable. Political action is needed to steer the behaviour of the business community and bring about much deeper and more lasting change at structural level. Such action cannot be decided based on the evolution of the GERD/GDP ratio, the number of researchers in the business sector, or any other kind of descriptive indicator. This type of action needs to promote change in the attitude of the economic agents towards R\&D. Deep cultural change among all the economic agents in the innovation system is required to design and implement effective S\&T policies that are based not on the mere evolution of figures and ratios, but on long-term structural changes. Only then will the sector's behaviour indicators shift, in the medium term, to reflect the values implied in the political messages.

The authors acknowledge the financial support received from the Spanish National R\&D Plan (Project ref.: SEJ2005-05923/EDUC and Francisco Javier Ortega-Colomer's grant: BES-2006-13425). Also, we feel indebted to Prof. Jordi Molas-Gallart and Prof. Ignacio Fernández-de-Lucio for their valuable comments and suggestions.

\section{References}

Albertos, J. M. (2002), Cultura, innovación y desarrollo local, Boletín de la AGE, 34, pp. 229-244.

Alto Consejo Consultivo De La CV., Informe anual sobre el estado de la investigación, el desarrollo y la tecnología en la Comunidad Valenciana. Presidencia de la Generalitat Valenciana, Valencia, 2008.

BRunEt, R. (2002), Lignes de force de l'espace européen, Mappe Monde, 66 (2) : 14-19 
Castro-Martínez, E., Fernández De Lucio, I., La I+D empresarial y sus relaciones con la investigación pública. In: J. SEBASTIÁn, E. MuÑoz (Eds), Radiografía de la Investigación Pública en España, Editorial Biblioteca Nueva, Madrid, pp. 348-372, 2006.

Chobanova, R., Policies for research and innovation on the move towards era, Paper to the conference Indicators on Science, Technology and Innovation History and New Perspectives. Lugano, 15-17 November, 2006.

COMmission of the EuRopean COMMUnities, Innovation Policy: updating the Union's approach in the context of the Lisbon strategy. COM 2003-112. Commission of the European Communities, Brussels, 2003.

COMMISSION OF THE EUROPEAN COMMUNITIES, 2006 European Regional Innovation Scoreboard (2006 RIS). http://rendchart.cordis.lu, 2007.

DíEZ, M. A. (2002), Evaluating new regional policies, Evaluation, 8 (3) : 285-305.

Feller, I., GAMOtA, G. (2007), Science indicators as reliable evidence, Minerva, 45: 17-30.

FernándeZ-De-Lucio, I., GutiérreZ-Gracia, A., JimÉneZ-SÁeZ, F., AZAGra-CARo, J. (2001), Las debilidades y fortalezas del Sistema Valenciano de Innovación en el inicio del siglo XXI. In: OLAZARÁN, M., GómeZ-UrangA, M. (Eds), Sistemas regionales de innovación. Universidad del País Vasco, Lejona, pp. 251-277.

García-Aracil, A., Fernández-De-Lucio, I., Azagra-Caro, J., López-Estornell, M. (2002), Análisis de las actividades de investigación y desarrollo y de cooperación entre las comunidades académica y empresarial de la Comunidad Valenciana, Revista valenciana d'estudis autonòmics, 38, pp. 39-104.

Generalitat Valenciana, Plan Valenciano de Investigación Científica, Desarrollo Tecnológico e Innovación (PVIDI). Presidencia de la Generalitat Valenciana, Valencia. http://www.edu.gva.es/poci/docs /objetivos.pdf, 2000.

GodIN, B. (2002), Are statistics really useful? Myths and politics of science and technology indicators. CSIIC working paper series No. 20. Canadian Science and Innovation Indicators Consortium, Montreal.

Godin, B. (2007), Science, accounting and statistics: the input-output framework, Research Policy, 36 : 1388-1403.

HiSPALINK, Spanish regional economic outlook: situación actual y perspectivas. Retrieved March 21, 2007 from http://www.hispalink.es, 2007.

INE, Estadística sobre actividades de I+D, año 2005. Instituto Nacional de Estadística, Madrid, (2007A).

INE, Indicadores de Alta Tecnología, año 2005. Instituto Nacional de Estadística, Madrid, (2007B).

INE, Encuesta sobre Innovación Tecnológica en las Empresas, año 2005. Instituto Nacional de Estadística, Madrid, (2007C).

INE, Contabilidad Regional de España, Base 2000. Instituto Nacional de Estadística, Madrid, (2007D).

INE, Estadística sobre actividades de I+D, año 2006. Instituto Nacional de Estadística, Madrid, (2008A).

INE, Estadística de enseñanza universitaria. Instituto Nacional de Estadística, Madrid, (2008B).

KATZ, S. (2006), Indicators for complex innovation systems, Research Policy, 35 : 893-909.

Legler, H., Rammer, C. H., Grenzmann, C. H., National Systems of Innovation in Comparison. Structure and Performance Indicators for Knowledge Societies. In: U. SCHMOCH, C. H. RAMMER, H. LEGLER (Eds), R\&D Activities in the German Business Sector, Springer, the Netherlands, pp. 17-30, 2006.

LEydesdorfF, L., MEYER, M. (2007), The scientometrics of a triple helix of university-industry-government relations, Scientometrics, 70 (2) : 207-222.

LIPSEY, R., CARLAW, K., A Structuralist Assessment of Technology Policies. Taking Schumpeter Seriously on Policy. Industry Canada Research Publications Program, Ottawa, 1998.

LiPsey, R., CARlaw, K., BeKar, C., Economic Transformations: General Purpose Technologies and Long Term Economic Growth. Oxford University Press, Oxford, 2005.

Lundvall, B. A., National Systems of Innovation: Towards a Theory of Innovation and Interactive Learning. Pinter, London, 1992.

MARTIN, B., The evolution of science policy and innovation studies, Conference held at the Institute INGENIO (CSIC-UPV), Valencia, 2008.

Mas, M., Pérez, F., Uriel, E., Serrano, L., Soler, A., Capital Humano en España y su distribución provincial. Banco de datos. Instituto Valenciano de Investigaciones Económicas (IVIE), Valencia. Retrieved March 21, from http://www.ivie.es/banco/capital.es, 2007. 
MEYER, M. (2006), Measuring science-technology interactions in the knowledge-driven economy: the case of a small economy, Scientometrics, 66 (2) : 425-439.

Ministerio DE LA PRESIDENCIA, Programa Ingenio 2010. Retrieved March 21, 2007 from http://ingenio2010.fecyt.es, 2005.

Molas-Gallart, J., DAVIES, A. (2006), Toward theory-led evaluation: the experience of the European science, technology and innovation policies, American Journal of Evaluation, 27 (1) : 64-82.

Moreau, F. (2004), The role of the state in evolutionary economics, Cambridge Journal of Economics, 28 (6) : 847-874.

OECD, Frascati Manual 2002: Proposed Standard Practice for Surveys on Research and Experimental Development. OECD Publishing, Paris, 2003.

OECD, The Measurement of Scientific and Technical Activities, Proposed Guidelines for Collecting and Interpreting Technological Innovation Data: Oslo Manual, $3^{\text {rd }}$ edition. OECD Publishing, Paris, 2005.

RUEGG, R., FELlER, I., A toolkit for evaluating public R\&D investment. National Institutes of Standards and Technology, Washington, DC, 2003.

SHAPIRA, P., Evaluating manufacturing extension services in the United States: Experiences and insights, In: P. SHAPIRA, S. KUHLMANN (Eds), Learning from Science and Technology Policy Evaluations, Edward Elgar, Cheltenham, pp. 260-292, 2003.

TASSEY, G., R\&D policy models and data needs, In: M. Feldman, A. LinK (Eds), Innovation Policy in the Knowledge-Based Economy, Kluwer, Boston, pp. 37-71., 2001.

Wong, P. K., Ho, Y. P. (2007), Knowledge sources of innovation in a small open economy: The case of Singapore, Scientometrics, 70 (2) : 223-249. 